\title{
Prevalence of asthma symptoms and smoking behavior among 20 - 44 years old adults in Tehran: A telephone survey
}

\author{
Behnaz Tazesh ${ }^{1}$, Azadeh Shaabani ${ }^{1}$, Mohammad Reza Fazlollahi ${ }^{{ }^{*}}$, Abbas Entezari ${ }^{2}$, \\ Raheleh Dashti ${ }^{1}$, Zahra Pourpak ${ }^{1}$, Mostafa Moin ${ }^{1}$ \\ ${ }^{1}$ Immunology, Asthma and Allergy Research Institute, Tehran University of Medical Sciences, Tehran, Iran; \\ *Corresponding Author: fazlollahi@sina.tums.ac.ir \\ ${ }^{2}$ Educational Developmental Center, Ministry of Health and Medical Education, Tehran, Iran
}

Received 31 December 2012; revised 8 February 2013; accepted 18 February 2013

\section{ABSTRACT}

Background and Objective: Asthma is a major health problem and a high-burden disease in the world. Unfortunately the prevalence of asthma in adult populations in Iran is not determined precisely. The aim of this study was to assess the prevalence of asthma symptoms and it's relation with ages, gender and smoking behaviour in city of Tehran. Methods: A telephone interview survey was conducted among $\mathbf{7 1 5 0}$ randomly selected telephone numbers in city of Tehran. A questionnaire adapted from The European Community Respiratory Health Survey (ECRHS) with additional two questions about smoking behaviour and hookah. Results: From 7150 eligible telephone numbers dialled there were 5500 responses $(76.92 \%)$. The study populations included 3412 female (62\%), 2088 men (38\%) and the mean age of responder were $31.15 \pm 7.33$. Their smoking behaviour were; $71.6 \%$ non smoker, $11.9 \%$ active smoker, $16.5 \%$ passive smoker and $7.8 \%$ used hookah. The prevalence of "wheezing in the last 12 months", "dyspnea with wheezing" and "wheezing and two nocturnal symptoms" were $24 \%, 10.8 \%$ and $5 \%$ respectively. Prevalence of asthma symptoms was significantly greater in smokers than non-smokers groups. Conclusion: In this study by using symptom based questionnaire (ECRHS), we concluded the prevalence of asthma in Tehran adult population was between $5 \%$ to $10 \%$. Also this study may made cross-national comparison of our findings with other ECRHS studies possible; rates of "wheezing in the last 12 months", "dyspnea with wheezing" and "nocturnal dyspnea" were higher than the European Community Respiratory Health
Survey median. Role of air pollution, smoking and other risk factors for asthma should be considered.

Keywords: Asthma; Adult; Prevalence; Smoking; Iran

\section{INTRODUCTION}

Asthma is a high-burden disease that has a mostly effective treatment [1]. The World Health Organization (WHO) has reported that around 300 million people in the world are affected by asthma, and this number is rising [2]. Increasing prevalence and morbidity and mortality related to bronchial asthma in the last decades, causes worldwide concern [3]. The cause of this increase in prevalence is unclear, but environmental factors, such as air pollution, smoking behaviour, living condition, diet and allergens may also be influencing the prevalence of asthma [4]. To assess the prevalence of asthma different methodologies have been used in various studies in the world, which causes comparison of findings in these studies not reliable. Thus, there have been attempts to standardize the methodology used for epidemiology of asthma [3,5]. Despite the fact that ECRHS (European Community Respiratory Health Survey) and International Studies of Asthma and Allergies in Childhood (ISAAC) has allowed comparison of prevalence of asthma and asthma-like symptoms between countries [3,6,7]; There are a few reports about asthma status in the WHO Eastern Mediterranean Region, including the Islamic Republic of Iran $[8,9]$.

Although active smoking is recognized as the most important risk factor for the development of chronic obstructive pulmonary disease [10], the complex relation between asthma and active smoking remains unclear. One might expects individuals with asthma would avoid 
smoking; surprisingly smoking is common in asthmatic people [11]. In some previous cross-sectional studies no difference was seen in smoking prevalence in people with or without asthma $[12,13]$. Another aspect of active smoking which rises concern in asthmatic patients is; its role in asthma severity [13], accelerating decline in lung function [14], impair therapeutic effect of inhaler corticosteroids [15] and interfering with asthma control (either worsen/weaken control) [16].

The aim of this study was to determine the prevalence of asthma symptoms and impact of smoking behaviour in adults aged 20 - 44 years in Tehran and to compare them with the same reports from other countries.

\section{METHODS}

This study was conducted in Tehran, capital of the Islamic Republic of Iran, with about 8 million populations. This city is situated at the foot of the Tochal mountain range in Western Asia. In the $20^{\text {th }}$ century, Tehran faced a large number of immigration from all over the country and most of Iranian industries are headquartered in Tehran.

This was a cross-sectional telephone interview study, which was conducted during winter and spring of 2010, 16,500 telephone numbers randomly selected from twenty two regional telecommunications of Tehran. Two trained general practitioner dialled with random numbers and invited all 20 - 44 years person to answer the questionnaires. If one number was busy, they repeat contact again. No proxy interviews were allowed. Interviews were conducted using a Persian description of the ECRHS questionnaire on asthma symptoms with two additional questions on smoking behaviours (Appendix 1).

Current asthma was defined by positive responses to question 5 or 6 . (Including that they had an attack of asthma in the last 12 months and/or that they were currently taking medication for asthma).

\subsection{Statistic Analysis}

The data were analysed using the statistical software SPSS, Version 16 (SPSS Inc., Chicago, IL, USA). The prevalence for each of the symptoms was calculated. A comparison between groups was made using the chisquared test and a $\mathrm{P}$ value lower than 0.05 was considered statistically significant.

\subsection{Ethics}

This study was approved by ethic committee of Immunology, Asthma and Allergy Research Institute. The condition of the study was explained to participants at the time of the telephone interview and explicit verbal consent was obtained before the questionnaire was in- troduced. All participants were confident that all personal information would be kept private.

\section{RESULTS}

We selected 16,500 telephone numbers. From 7150 eligible telephone number, 1650 numbers refused to answer. Therefore, the response rate was $76.92 \%$ (5500).

The age range of people who participated in the study were 20 - 44 years, with a mean age of $31.15 \pm 7.33$ years. The number of women was 3412 (62\%) Table 1 shows the division of the study population by sex and smoking behaviour. In active smoker group $10.1 \%$ were men and $1.8 \%$ women. In this study, women had lower prevalence of smoking.

Table 2 shows frequency of respiratory symptoms, asthma attack and use of medicine for asthma (oral, inhaler or parentral) in both genders.

There was significant difference among gender with wheezing, wheezing with dyspnea and wheezing without cold $(\mathrm{P}<0.001)$. However there was no significant difference among gender and feeling of tightness in chest, attack of shortness of breath, waking up with cough, attack of asthma and current asthma $(\mathrm{P}>0.05)$.

The result of wheezing prevalence and two nocturnal symptoms were analysed (Nocturnal chest tightness and/ or Nocturnal dyspnea) which there was no significant difference among gender with these symptoms.

In active smokers the prevalence of wheezing, wheezing without cold, nocturnal dyspnea, nocturnal chest tightness, nocturnal cough, current asthma, wheeze and nocturnal dyspnea, wheezing and two nocturnal symptoms were significantly higher than non smokers group.

In smokers more than 10 cigarettes per day the frequency of wheezing, wheezing with dyspnea, wheezing without cold, nocturnal dyspnea, nocturnal cough, wheeze and nocturnal dyspnea, wheezing and two nocturnal symptoms were significantly higher than in less than 10 cigarettes per day group.

In passive smoker group the prevalence of wheezing,

Table 1. Prevalence of smoking behavior in 20 - 44 year old adults in Tehran.

\begin{tabular}{cccc}
\hline $\begin{array}{c}\text { Smoking } \\
\text { habit/Gender }\end{array}$ & Males $(\boldsymbol{n = 2 0 8 8})$ & $\begin{array}{c}\text { Female } \\
(\boldsymbol{n}=\mathbf{3 4 1 2})\end{array}$ & Total $(\boldsymbol{n}=\mathbf{5 5 0 0})$ \\
\hline $\begin{array}{c}\text { Active smoker* } \\
\text { More than } 10\end{array}$ & $553(10.1 \%)$ & $101(1.8 \%)$ & $654(11.9 \%)$ \\
cigarettes per day $^{* *}$ & $223(34 \%)$ & $23(3.5 \%)$ & $246(37.6 \%)$ \\
$\begin{array}{c}\text { Passive smoker } \\
\text { Hookah (pipe } \\
\text { water) }\end{array}$ & 293(5.3\%) & $615(11.2 \%)$ & $908(16.5 \%)$ \\
Non smoker $^{*}$ & $1242(22.6 \%)$ & $2496(49 \%)$ & $3938(71.6 \%)$ \\
\hline
\end{tabular}

${ }^{*} \%$ within total, ${ }^{* *} \%$ within active smoker group. 
Table 2. Prevalence of respiratory symptoms according to gender.

\begin{tabular}{|c|c|c|c|c|}
\hline Symptoms & $\begin{array}{c}\text { Men } \\
(n=2088)\end{array}$ & $\begin{array}{c}\text { Women } \\
(n=3412)\end{array}$ & $\begin{array}{c}\text { Total } \\
(n=5500)\end{array}$ & P value \\
\hline $\begin{array}{c}\text { Wheezing in the last } \\
12 \text { months } \\
\text { (Wheezing) }\end{array}$ & $30.5 \%{ }^{*}$ & $20.1 \%$ & $24 \%$ & $<0.001$ \\
\hline $\begin{array}{l}\text { Wheezing with } \\
\text { breathlessness in the } \\
\text { last } 12 \text { months } \\
\text { (Dyspnea with } \\
\text { wheezing) }\end{array}$ & $37.1 \%$ & $52.8 \%$ & $10.8 \%$ & $<0.001$ \\
\hline $\begin{array}{l}\text { Wheezing without } \\
\text { cold }\end{array}$ & $52.7 \%$ & $44.5 \%$ & $11.5 \%$ & $<0.001$ \\
\hline $\begin{array}{l}\text { Waking up with } \\
\text { feeling of tightness in } \\
\text { the last } 12 \text { months } \\
\text { (Nocturnal chest } \\
\text { tightness) }\end{array}$ & $11.4 \%$ & $1.3 \%$ & $11.3 \%$ & $P=0.732$ \\
\hline $\begin{array}{l}\text { Waking up with } \\
\text { shortness of breath in } \\
\text { the last } 12 \text { months } \\
\text { (Nocturnal dyspnea) }\end{array}$ & $10 \%$ & $10.7 \%$ & $10.4 \%$ & $\mathrm{P}=0.543$ \\
\hline $\begin{array}{l}\text { Waking up with } \\
\text { attack of coughing } \\
\text { (Nocturnal cough) }\end{array}$ & $10 \%$ & $10.7 \%$ & $10.4 \%$ & $P=0.543$ \\
\hline Attack of asthma & $1.5 \%$ & $1.7 \%$ & $1.6 \%$ & $\mathrm{P}=0.594$ \\
\hline $\begin{array}{l}\text { Use of medicine for } \\
\text { asthma (Asthma } \\
\text { medications) }\end{array}$ & $1.7 \%$ & $2.1 \%$ & $1.9 \%$ & $P=0.324$ \\
\hline $\begin{array}{l}\text { Wheeze and } \\
\text { Nocturnal dyspnea }\end{array}$ & $5.1 \%$ & $5 \%$ & $5 \%$ & $P=0.412$ \\
\hline $\begin{array}{l}\text { Wheezing and two } \\
\text { nocturnal symptoms }\end{array}$ & $5.1 \%$ & $5 \%$ & $5 \%$ & $P=0.412$ \\
\hline Current asthma & $0.7 \%$ & $1.3 \%$ & $2 \%$ & $\mathrm{P}=0.278$ \\
\hline
\end{tabular}

*\% within sex.

wheezing with dyspnea, nocturnal dyspnea, nocturnal chest tightness, and nocturnal cough were significantly higher than non smokers.

In Hookah (pipe water) wheezing and nocturnal chest tightness symptoms had significantly higher frequency than non smokers (Table 3).

\section{DISCUSSION}

Defining asthma may be problematic in epidemiological studies. Most of surveys have used symptoms based questionnaire, which may cause problems arising from subjective reasons. Survey instruments generally are supported and tested by subjective methods, preferably gold standard test. Despite this fact; there is no gold standard test for asthma diagnosis. A standardized questionnaire which can be used in different regions of the world to verify geographical variation in asthma and other allergic disease; may overcome the potential problems of both subjective questionnaire and expensive methods such as bronchial hyper responsiveness (BHR). The ECRHS study is the first study to evaluate a geographical variation in asthma in adults and due to its noncultural nature it has been conducted in 22 different countries [6,17].

According to Swedish Study of Air Pollution and Lung Disease in Adult (SPALDIA) wheezing in whatever forms, has a high diagnostic value as a symptom in asthma diagnosis. Also wheezing and two nocturnal symptoms (chest tightness, dyspnea and cough) have a high sensitivity and specificity for asthma diagnosis. Both wheezing and wheezing with two nocturnal symptoms yield best Yoden index (which evaluate the diagnostic efficacy of a test) [5] meanwhile there was a survey which has scored each of asthma symptoms that has been used in ECRHS study to evaluate questionnaire based diagnosis versus clinical diagnosis. In this scoring study, "wheezing and dyspnea" has highest score as symptomatic asthma [17]. In our study prevalence of "wheezing in last 12 months", "wheezing with dyspnea" and "wheezing with two nocturnal symptoms" were $24 \%, 10.8 \%$ and $5 \%$ respectively.

So according to both SPALDIA and ECRHS scoring studies "wheezing with dyspnea" and "wheezing with two nocturnal symptoms" are more likely to resemble clinical diagnosis of asthma in questionnaire based surveys $[5,17]$. Therefore, by using this two symptoms ,we can estimate prevalence of asthma in Tehran could be between $5 \%$ to $10 \%$.

Using a standardized questionnaire enabled us to compare our results with other countries [18]. The prevalence of asthma (according to ECRHS) was higher in Australia and New Zealand and lowest in Estonia, Algeria and India [19]. The prevalence of wheezing and dyspnea in our survey was $10.8 \%$ which is a little more than ECRHS median (9.8\%) and lower than Turkey (15.4\%), United Kingdom (13.9\%) and higher than India (3\%) (Table 4).

In our study prevalence of "current asthma" is $2 \%$. This prevalence is lower than ECRHS median (4.5\%), the reason could be that asthma is an under diagnosed disease in Iran and the wax and wane nature of asthma itself. Other potential problem may be subjective symptoms recognition or recall and tendencies to hide illness for social reasons.

Many studies have stated that smoking increases severity of airways inflammation and related respiratory symptoms in asthmatic patients and normal population [20]. It is estimated that there are about 4 million death due to smoking in the world and it is going to rise to 8.4 million death per year by 2020, and $66 \%$ of them will be in developing countries [20]. In our study prevalence of smoking was $11.9 \%$ ( $10.1 \%$ men vs. $1.8 \%$ women) which in comparison to results of national survey of non communicable disease in Iran $(14.8 \%$ overall, $26.1 \%$ 
men, 3.2\% women) is lower because we categorized people who had smoked water pipe in a different group [21]. In Uromia (a province in North West of Iran), prevalence of smoking was $3.6 \%$ in women and $30.5 \%$ in men [22]. In other study in Tehran the overall cigarette smoking was $11.3 \%$ which is similar to our study [23]. The prevalence of smoking in adult men in European countries varies from the lowest rate in Sweden (14.9\%) to the highest in Russia (65\%). The prevalence of smoking among men in Tehran in our survey was lower than all European countries [24].

The prevalence of smoking water pipe in our study was (overall 7.8\%: 5.1\% men, 2.7\% women). However according to national survey of non communicable disease in Iran; water pipe is the most form of tobacco use in Iranian women and they may not use it regularly but in many occasions [21]. As it shown in Table 3 water pipe smoking has a significant relationship with "wheezing", which may alert us about upcoming asthma symptoms in water pipe smokers in next few years. Moreover; "wheezing” was significantly higher in active smokers vs. non smokers. There was also significant relationship between smoking and "wheezing and two nocturnal symptoms” ( $\mathrm{P}<0.05-\mathrm{OR} 2.12)$, Another finding was that

Table 3. Prevalence of asthma symptoms and their associations with smoking behavior.

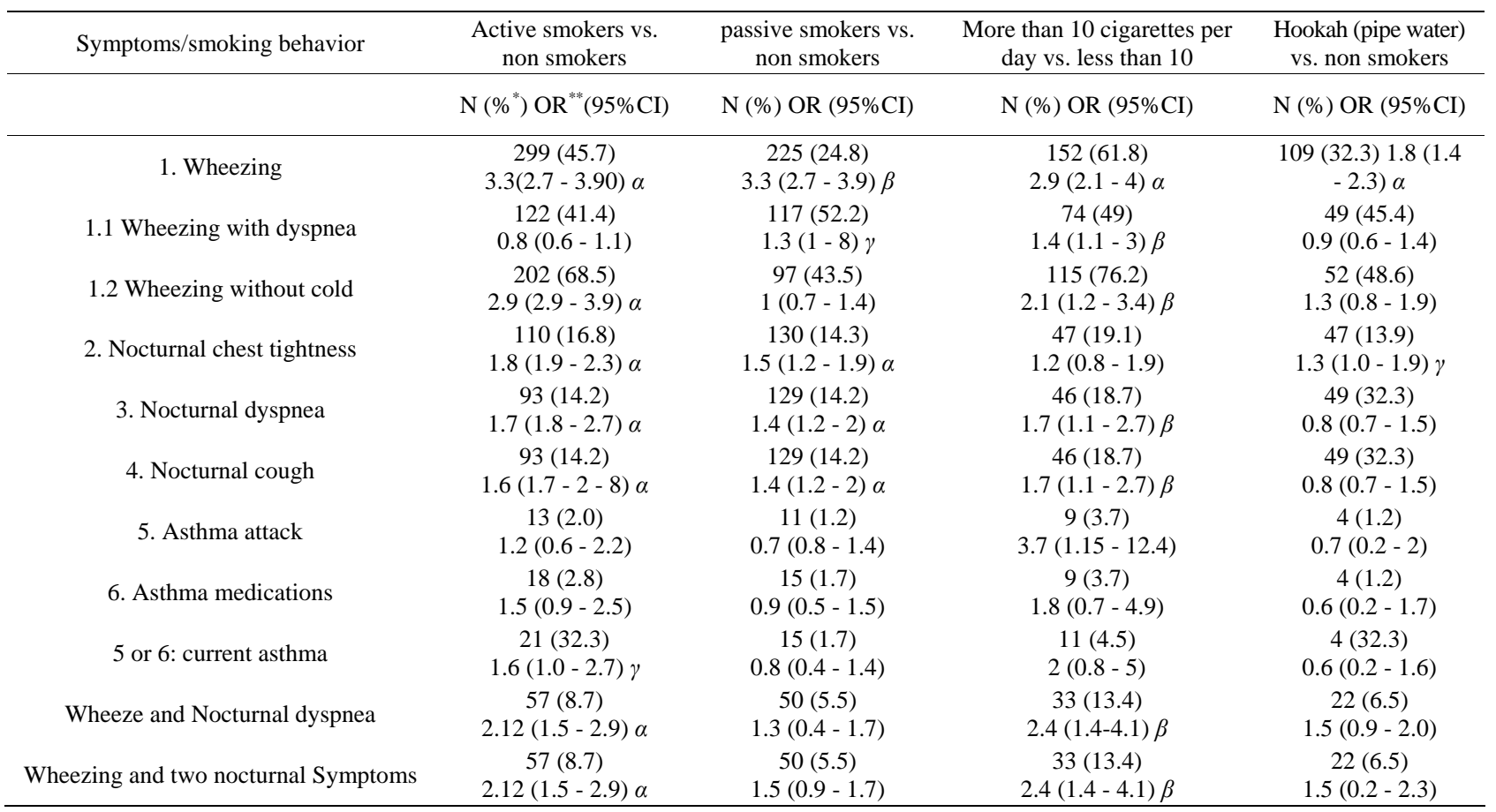

$\alpha=\mathrm{P}<0.001, \beta=\mathrm{P}<0.01, \gamma=\mathrm{P}<0.05,{ }^{*} \%$ within each smoker group, ${ }^{* *} \mathrm{OR}$ : odd ratio.

Table 4. Comparison of the prevalence of adult asthma symptoms found in Iran (Tehran) with some of the centers participated in ECRHS and the European Community Respiratory Health Survey (ECRHS) median (48 centers) $\beta$. $\alpha$ : current study, $\beta$ : adopted from ECRHS study [25], $\gamma$ : not reported.

\begin{tabular}{|c|c|c|c|c|c|c|c|c|c|}
\hline Country/symptoms & Wheezing & $\begin{array}{c}\text { Wheezing with } \\
\text { dyspnea }\end{array}$ & $\begin{array}{l}\text { Wheezing } \\
\text { without cold }\end{array}$ & $\begin{array}{c}\text { Nocturnal chest } \\
\text { tightness }\end{array}$ & $\begin{array}{l}\text { Nocturnal } \\
\text { dyspnea }\end{array}$ & $\begin{array}{l}\text { Nocturnal } \\
\text { cough }\end{array}$ & $\begin{array}{l}\text { Asthma } \\
\text { attack }\end{array}$ & $\begin{array}{c}\text { Asthma } \\
\text { medications }\end{array}$ & $\begin{array}{l}\text { Current } \\
\text { asthma }\end{array}$ \\
\hline 1. Iran (Tehran) $\alpha$ & 24 & 10.8 & 11.5 & 11.3 & 10.4 & 10.4 & 1.6 & 1.9 & 2 \\
\hline 2. Norway ( Bergen) & 24.6 & 13.6 & 15.8 & 11.4 & 5 & 26.1 & 3.1 & 3.4 & 4.3 \\
\hline 3. Germany (Hamburg) & 21.1 & 8 & 13.3 & 9.6 & 5 & 25.8 & 3 & 3.4 & 4.4 \\
\hline 4. France (Paris) & 14.5 & 9.3 & 9 & 16.8 & 4.7 & 26 & 4.3 & 3.2 & 5.1 \\
\hline 5. UK (Cambridge ) & 25.2 & 13.9 & 17.7 & 17.4 & 8.4 & 27.7 & 5.7 & 6.8 & 8.4 \\
\hline 6. Greece (Athens) & 16 & 9.4 & 9.8 & 11.7 & 5.7 & 17.8 & 2.4 & 2.2 & 2.9 \\
\hline 7. Turkey (5 centers) & 24.9 & 15.4 & 13 & NR $\gamma$ & 17.1 & 16.8 & NR $\gamma$ & NR $\gamma$ & 6.6 \\
\hline 8. India (Bombay) & 4.1 & 3 & 2 & 7 & 6.8 & 11.2 & 2.6 & 2.8 & 3.5 \\
\hline 9. ECRHS (median) & 20.7 & 9.8 & 12.7 & 13.5 & 7.3 & 27.9 & 3.1 & 3.5 & 4.5 \\
\hline
\end{tabular}


the prevalence of "wheezing and dyspnea" was higher in passive smoker than non-smokers $(\mathrm{P}<0.001)$, which means that active and passive smokers are more likely to develop asthma symptoms.

\section{CONCLUSION}

In this study the prevalence of asthma symptoms in Tehran was found to be a little more than ECRHS median. All asthma symptoms were more likely to happen in active smokers and "wheezing with dyspnea" in passive smoker was much higher than non-smoker, which indicates smoking as a serious risk factor for asthma among adult population. So it is recommended; to conduct further multinational surveys to estimate prevalence of asthma and influence of smoking behaviour in Eastern Mediterranean region.

\section{REFERENCES}

[1] Marks, G.B., Abramson, M.J., Jenkins, C.R., Kenny, P., Mellis, C.M., Ruffin, R.E., Stosic, R. and Toelle, B.G. (2007) Asthma management and outcomes in Australia: A nation-wide telephone interview survey. Respirology, 12, 212-219. doi:10.1111/j.1440-1843.2006.01010.x

[2] Bousquet, J., Clark, T., Hurd, S., Khaltaev, N., Lenfant, C., O’byrne, P., et al. (2007) GINA guidelines on asthma and beyond. Allergy, 62, 102-112. doi:10.1111/j.1398-9995.2006.01305.x

[3] Demir, A.U., Kalyoncu, A.F., Seluk, T., Artvinli, M. and Sahin, A. (2001) Prevalence of asthma, allergy, and respiratory symptoms in Hasançelebi/Hekimhan/Malatya in Eastern Turkey. Turkish Respiratory Journal, 2, 29-34.

[4] Manfreda, J., Becklake, M.R., Sears, M.R., et al. (2001) Prevalence of asthma symptoms among adults aged 20-44 years in Canada. Canadian Medical Association Journal, 164, 995-1001.

[5] Sistek, D., Tschopp, J.-M., Schindler, C., Brutsche, M., Ackermann-Liebrich, U., Perruchoud, A,-P., Leuenbergerz, P. and SAPALDIA Team (2001) Clinical diagnosis of current asthma: Predictive value of respiratory symptoms in the SAPALDIA study. European Respiratory Journal, 17, 214-219.

doi:10.1183/09031936.01.17202140

[6] Burney, R.G.J., Luczynska, S., Chinn, S. and Jarvis, D. (1994) The European Community respiratory health survey. European Respiratory Journal, 7, 954-960. doi:10.1183/09031936.94.07050954

[7] Asher, M.I., Keil, U., Anderson, H.R., Besley, R., Crane, J., Martinez, F., Mitchell, E.A., Pearce, N., Sibbald, B., Stewart, A.W., Strachan, D., Weiland, S.K. and Williams, H.C. (1995) International study of asthma and allergy in childhood (ISAAC): Rationale and methods. European Respiratory Journal, 8, 483-491. doi:10.1183/09031936.95.08030483

[8] Boskabady, M.H. and Kolahdoz, G.H. (2002) Prevalence of asthma symptoms among the adult population in the city of Mashhad (northeast of Iran). Respirology, 7, 267272. doi:10.1046/j.1440-1843.2002.00398.x

[9] Golshan, M., Esteki, B. and Dadvand, P. (2002) Prevalence of self-reported respiratory symptoms in rural areas of Iran in 2000. Respirology, 7, 129-132. doi:10.1046/j.1440-1843.2002.00375.x

[10] Fletcher, C. and Peto, R. (1977) The natural history of chronic airflow obstruction. British Medical Journal, 1, 1645-1648.

[11] Thomson, N.C., Chaudhuri, R. and Livingston, E. (2004) Asthma and cigarette smoking. European Respiratory Journal, 24, 822-833.

[12] Zimlichman, E., Mandel, D., Mimouni, F.B., Shochat, T., Grotto, I. and Kreiss, Y. (2004) Smoking habits in adolescents with mild to moderate asthma. Pediatric Pulmonology, 38, 193-197.

[13] Siroux, V., Pin, I., Oryszczyn, M.P., Le Moual, N. and Kauffmann, F. (2000) Relationships of active smoking to asthma and asthma severity in the EGEA study. Epidemiological study on the genetics and environment of asthma. European Respiratory Journal, 15, 470-477.

[14] Lange, P., Parner, J., Vestbo, J., Schnohr, P. and Jensen, G. (1998) A 15-year follow-up study of ventilatory function in adults with asthma. The New England Journal of Medicine, 339, 1194-1200.

[15] Chaudhuri, R., Livingston, E., McMahon, A.D., Thomson, L., Borland, W. and Thomson, N.C. (2003) Cigarette smoking impairs the therapeutic response to oral corticosteroids in chronic asthma. American Journal of Respiratory and Critical Care Medicine, 168, 1308-1311.

[16] Chaudhuri, R., McSharry, C., McCoard, A., Livingston, E., Hothersall, E., Spears, M., et al. (2008) Role of symptoms and lung function in determining asthma control in smokers with asthma. Allergy, 63, 132-135.

[17] Grassi, M., Rezzani, C., Biino, G. and Marinoni, A. (2003) Asthma-like symptoms assessment through ECRHS screening questionnaire scoring. Journal of Clinical Epidemiology, 56, 238-247. doi:10.1016/S0895-4356(02)00613-3

[18] Sunyer, J., Basagana, X., Burney, P. and Antom, J.M. (2000) International assessment of the internal consistency of respiratory symptoms. American Journal of Respiratory and Critical Care Medicine, 162, 930-935.

[19] Luczynska, C., Neukirch, F., Svanes, C., Sunyer, J., Wjst, M. and European Community Respiratory Health Survey II (2001) The European Community Respiratory Health Survey: What are the main results so far? European Respiratory Journal, 18, 598-611 doi:10.1183/09031936.01.00205801

[20] Warren, C.W., Riley, L., Asma, S., Eriksen, M.P., Green, L., Blanton, C., Loo, C., Batchelor, S. and Yach, D. (2000) Tobacco use by youth: A surveillance report from the global youth tobacco survey project. Bulletin of the World Health Organization, 78, 868-876.

[21] Meysamie, A., Ghaletaki, R., Haghazali, M., Asgari, F., Rashidi, A., Khalilzadeh, O., et al. (2010) Pattern of tobacco use among the Iranian adult population: Results of the national survey of risk factors of non-communicable disease (SuRFNCD-2007). Tobacco Control, 19, 125-128. 
doi:10.1136/tc.2009.030759

[22] Rahimi-Rad, M., Gaderi-Pakdel, F. and Salari-Lak, S. (2008) Smoking and asthma in 20 - 44 year old adults in urmia, Islamic Republic of Iran. Eastern Mediterranean Health Journal, 14, 6-76.

[23] Ahmadi, J., et al. (2001) Prevalence of cigarette smoking in Iran. Psychological Reports, 89, 339. doi:10.2466/pr0.2001.89.2.339

[24] Control, R. (2008) WHO report on the global tobacco

\section{APPENDIX 1}

The following questions were used in our study (adapted from ECRHS):

1) Have you had wheezing or whistling in your chest at any time in the last 12 months?

a) Have you been at all breathless when the wheezing noise was present?

b) Have you had this wheezing or whistling when you did not have cold?

2) Have you woken up with a feeling of tightness in your chest at any time in the last 12 months?

3) Have you been woken by an attack of shortness of epidemic, 2008: The MPOWER package. World Health Organization.

[25] European Community Respiratory Health Survey (1996) Variations in the prevalence of respiratory symptoms, self-reported asthma attacks, and use of asthma medication in the European Community Respiratory Health Survey (ECRHS). European Respiratory Journal, 9, 687695.

breath at any time in the last 12 months?

4) Have you been woken by an attack of coughing at any time in the last 12 months?

5) Have you had an attack of asthma in the last 12 months?

6) Are you currently taking any medicine (including inhalers, aerosols or tablets) for asthma?

7) Smoking: no passive active (less than 10 cigarette/ day more than 10 cigarette/day).

8) Hookah (water pipe): yes no. 